\title{
Beware of the ambiguous enemy of Multisystem Inflammatory Syndrome in Adult (MIS-A) following Covid-19 infection or vaccination.
}

\author{
Ahmad Al Bishawi ${ }^{1}$, Maisa Ali ${ }^{1}$, Khaled Al-Zubaidi ${ }^{1}$, and Hamad Abdel Hadi ${ }^{1}$ \\ ${ }^{1}$ Hamad Medical Corporation
}

September 29, 2021

\begin{abstract}
Multisystem Inflammatory Syndrome is a rare and novel clinical presentation described during the evolving Covid- 19 pandemic. The condition is usually presenting as a sepsis-like syndrome leading to secondary multiorgan dysfunction post-COVID-19 infection. Although the syndrome has been mainly described in children, rare adults' form has been similarly described.

\section{Hosted file}

MIS-A_Final_of_Final_edited 1.docx available at https://authorea.com/users/438539/articles/ 539732-beware-of-the-ambiguous-enemy-of-multisystem-inflammatory-syndrome-in-adult-misa-following-covid-19-infection-or-vaccination
\end{abstract}

